\title{
Hazkundea, heltzea eta lesioak gizonezkoen goi-mailako futbolari gazteetan
}

(Growth, maturation and injuries in elite football players)

\author{
Xabier Monasterio*1, Susana M. ${ }^{a}$ Gil $^{1}$, Jon Larruskain ${ }^{2}$, Jose Antonio Lekue ${ }^{1,2}$, \\ Iraia Bidaurrazaga-Letona ${ }^{1}$
}

${ }^{1}$ Fisiologia Saila, Medikuntza eta Erizaintza Fakultatea (UPV/EHU)

${ }^{2}$ Zerbitzu Medikoak, Athletic Club

LABURPENA: Lesioak oso ohikoak dira gizonezkoen goi-mailako futbol taldeetan, eta jokalarien garapenean eta osasunean ondorio negatiboak dituzte. Hori dela eta, futbolarien lesioetan eragina izan dezaketen arrisku-faktoreak identifikatzea ezinbestekoa da. Azken urteotan egindako ikerketen arabera, hazkundeak eta heltzeak lesioen agerpenarekin erlazioa dutela aztertu arren, eragina ez dago guztiz argi eta kontraesanak daude. Lan honetan, hazkundearen eta heltzearen kontzeptu nagusiak laburbildu eta horien eta lesioen arteko harreman posibleak azaltzen dira.

HITZ GAKOAK: futbola, lesioak, hazkunde, heltzea.

ABSTRACT: Injuries are very frequent in elite male football academies and have a negative impact on players' development and health. Thus, identifying injury risk factors is vital. According to recent research, growth and maturity are related with injury occurrence. Nonetheless, the effects are not clear and results are controversial. In this article, we explain the main concepts of growth and maturity and their possible relationship with injury epidemiology.

KEYWORDS: football, injuries, growth, maturity.

\footnotetext{
* Harremanetan jartzeko / Corresponding author: Xabier Monasterio. Fisiologia Saila, Medikuntza eta Erizaintza Fakultatea (UPV/EHU), Sarriena auzoa s/n, 48940 Leioa, Bizkaia (Espainia). - xabier.monasterio@ehu.eus - https://orcid.org/00000001-9409-0059.

Nola aipatu / How to cite: Monasterio, Xabier; Gil, Susana M.; Larruskain, Jon; Lekue, Jose Antonio; Bidaurrazaga-Letona, Iraia (2020). «Hazkundea, heltzea eta lesioak gizonezkoen goi-mailako futbolari gazteetan»; Ekaia, 38, 2020, 117-128. (https://doi.org/10.1387/ekaia.21651).

Jasoa: 14 apirila, 2020; Onartua: 30 maiatza, 2020.

ISSN 0214-9001 - eISSN 2444-3255 / (C) 2020 UPV/EHU
}

(c) (i) () Obra hau Creative Commons Atribución 4.0 Internacional-en lizentziapean dago 
Xabier Monasterio, Susana M. ${ }^{a}$ Gil, Jon Larruskain, Jose Antonio Lekue, Iraia Bidaurrazaga-Letona

\section{SARRERA}

Goi-mailako futbol taldeek baliabide ugari inbertitzen dituzte profesional izatera hel daitezkeen jokalariak garatu nahian. Lesioak oso ohikoak dira goi-mailako futbolari gazteetan [1], eta, ez hori bakarrik, gainera baja denbora luzeak eragiten dituzte [2]. Lesioek hainbat ondorio negatibo izan ditzakete, hala nola ondorio ekonomikoak [3], taldearen errendimenduaren gutxitzea [4], berriro lesionatzeko arriskua edo nagusitan osasun-arazoak izateko arriskua handitzea [5]. Are gehiago, lesioek goi-mailako futbol taldeetan jarraitzeko aukerak gutxitzen dituzte [6]. Hori dela eta, lesioak prebenitzea ezinbestekoa da eliteko futbol-akademietan.

Futbol-akademietako lesioen epidemiologia adinaren arabera antolaturiko kategorien arabera aldatzen da [1]. Horrela, lesioen ondoriozko baja denbora maximoa nerabezaro inguruan agertzen da, alegia, 14 urte inguruko jokalarietan. Era berean, lesioen intzidentzia maximoa (lesio kopuru maximoa denboraldian zehar) adin horren inguruan agertzen da [7]. Hain zuzen ere, nerabezaroan zehar, jokalariek aldaketa antropometrikoak [8-10], biomekanikoak [11] eta neuromuskularrak [12] jasaten dituzte. Literaturaren arabera, bai aldaketa horiek eta baita futbolarien espezializazio goiztiarrak ere [13], akademiako jokalarien lesio-arriskuarekin harremana izan dezakete. Hala ere, heltzearen, hazkundearen eta lesioen arteko harremana futbolari gazteetan ez dago guztiz argi [5].

\section{HAZKUNDE ETA HELTZE KONTZEPTU OROKORRAK}

\section{A. Hazkunde-abiadura eta altueraren puntako abiadura}

Denok ezagutzen dugu «egun batetik bestera» asko hazi eta gorputza guztiz aldatu zaion norbait. Kirolari batean gorputzaren proportzioen aldaketa horiek (bai altueran, bai pisuan) geldotasuna eta baldartasuna eragiten dute [12]. Are gehiago, askotan, gorputzaren aldaketa bizkorrek eragindako ondorio negatibo horiek kirolarien progresio eta garapena moteltzea eragin dezakete. Moteltze hori konpentsatu nahian, entrenamenduetan entrenatzaile askok jokalariei gehiago exijitzen diete, eta horrek hazkunde lesioen agerpena eragin dezake [14]. Azken finean, «hauskorragoak» diren jokalari horietan egoera konpentsatu nahiak askotan jokalarien lesionatzea eta, ondorioz, jokalarien progresioa gelditzea edo akademiatik kanporatzea eragin dezake [6].

Hazkunde-prozesua gorputzeko dimentsioen handitzean datza, eta, eskuarki, aldagai antropometrikoen bidez neurtzen da, hala nola altuera, pisua edo gorputzeko segmentuen luzera (hanken luzera, enborraren altuera edo beso-zabalera). Hazkunde-abiadurak aldagai horien aldaketa aztertzen du denbora tarte konkretu batean; esate baterako, cm/urtetan [15-16]. Haz- 
kunde abiaduraren handiagotzen denean, growth spurt deritzon momentua heltzen da (1. irudia); hain zuzen ere, hazkunde-abiadurarik altuena agertzen den momentua (1. taula). Growth spurt horretan, altueraren puntako abiadura lortzen da; ingelesez peak height velocity (PHV) deritzona. PHV 13,8 urte inguruan gertatzen da mutiletan, eta 7,1-10,9 cm/urte bitarteko hazkunde-abiadurak izaten dira (1. irudia). Nesketan, ordea, arinago agertzen da (11,8 urte inguruan), eta hazkunde-abiadura 5,44-9,97 cm/urte bitartekoa izaten da. [15]. Bitxia badirudi ere, growth spurta ez da gorputzeko atal edota segmentu guztietan aldi berean agertzen. Gorputz-hazkuntza beheko gorputz-adarretako alde distaletatik hasi; ondoren, goiko gorputz-adarretatik jarraitu, eta, azkenik, enborra hazten da [16].

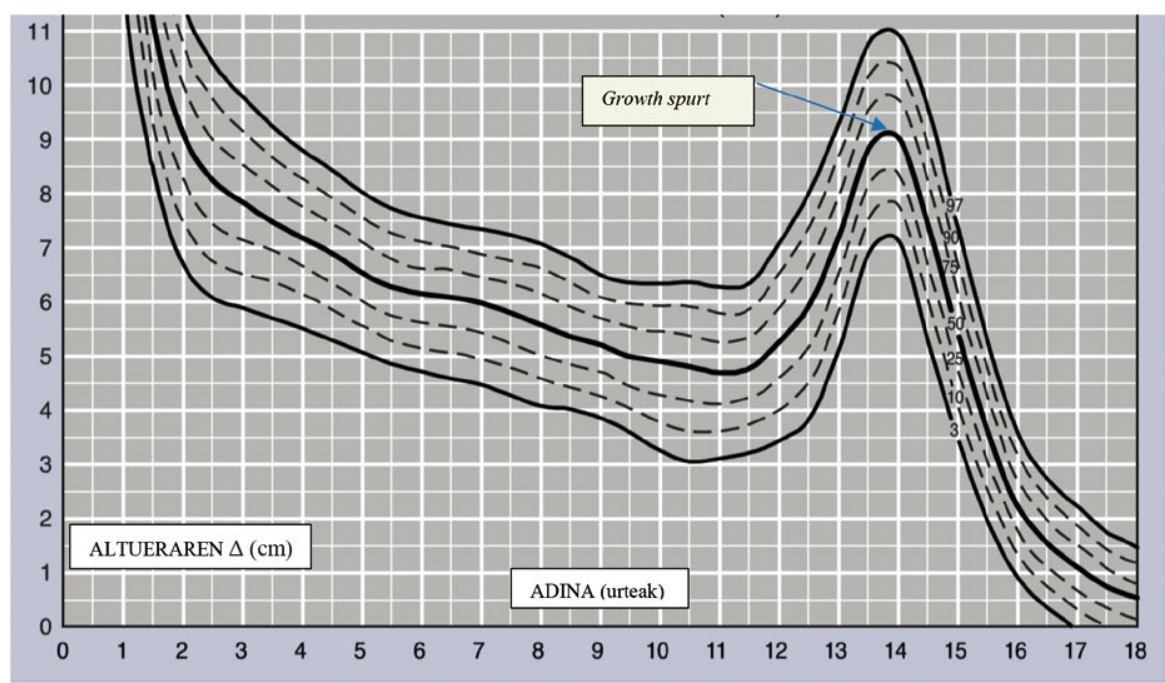

1. irudia. Hazkunde-kurba gizonezkoetan euskal gazteetan egindako ikerketa longitudinalaren arabera [15]. Hazkunde-abiadura adin bakoitzean pertzentiletan. 
Xabier Monasterio, Susana M. ${ }^{a}$ Gil, Jon Larruskain, Jose Antonio Lekue, Iraia Bidaurrazaga-Letona

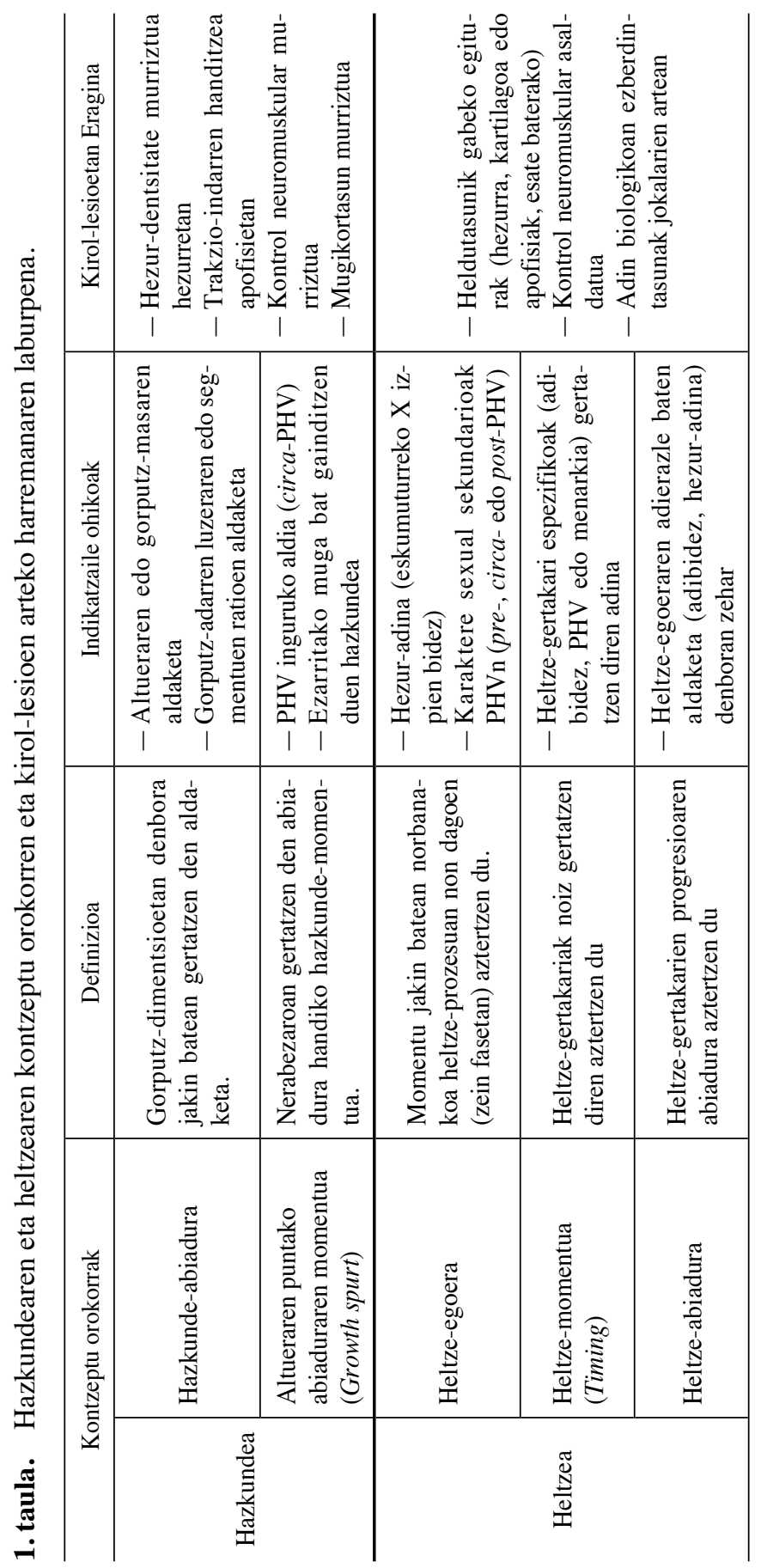




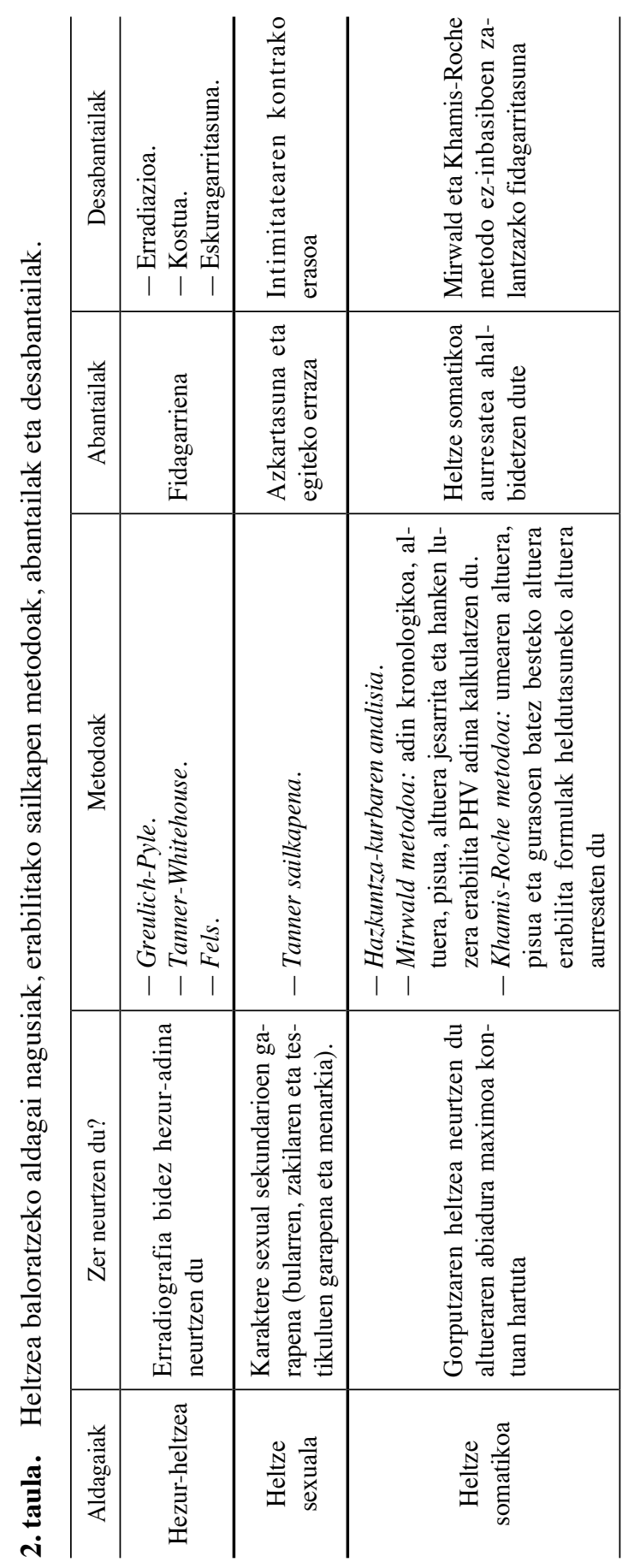


Xabier Monasterio, Susana M. ${ }^{a}$ Gil, Jon Larruskain, Jose Antonio Lekue, Iraia Bidaurrazaga-Letona

\section{B. Heltze-egoera, heltze-momentua eta heltze-erritmoa}

Heltzea hazkunde baino kontzeptu konplexuagoa eta zalantzagarriagoa da. Izan ere, heltzea, heldua izan arte gertatzen den trantsizio-prozesua deskribatzen duen terminoa dela esan dezakegu. Jokalari batek momentu zehatz batean duen heltze-mailari heltze-egoera deritzogu. Heltze-egoera hiru ikuspuntu edo sistema kontuan hartuta aztertzen da. Batetik, heltze eskeletikoa (hezur-adina kontuan hartzen duena); bestetik, heltze sexuala (sexu-karaktere sekundarioen garapena aztertzen duena) eta, azkenik, heltze somatikoa (gorputzeko atalak kontuan hartzen dituena) [16]. Karaktere sexual sekundarioen bidezko balorazioak fidagarritasun eskasa du, eta, gainera, intimitatearen kontrako erasotzat har daiteke. Hori dela eta, heltzeegoera baloratzeko gold-standarda, alegia, gehien erabiltzen den metodoa, hezur-adina da. Hezur-adina neurtzeko X izpien bitartez karpoko hezurren garapen-maila neurtzen da. Horrela, erradiografia horiek erreferentziazko estandarrak diren beste metodo batzuekin konparatzen dira umearen heltzea kalkulatzeko. Hala ere, $\mathrm{X}$ izpiek igorritako erradiazioak osasunean kalteak eragin ditzakeenez, heltze-egoera somatikoa neurtzen duten beste metodo batzuk proposatu dira, hala nola Mirwald eta Khamis-Roche metodoak [17-18] (2. taula). Heltze somatikoak hiru fase bereizten ditu; PHV aurreko fasea (pre-PHV), PHV inguruko fasea (circa-PHV) eta PHV osteko fasea (post-PHV) [17]. Khamis-Roche metodoak, umearen altuera, pisua eta gurasoen batez besteko altuera formula batean sartuz ume horren azkeneko edo heldutasuneko altuera aurresaten du. Horrela, jokalariaren altuera, aurresandako azkeneko altuera horren zein ehunekotan dagoen kalkula daiteke erraz. Hori jakinda, jokalaria pre-PHV-n (ehuneko hori \% 88 baino txikiagoa bada), circa-PHV-n (\% 88-96) edo post-PHV-n (>\% 96) dagoen aztertu dezakegu. Gorputzaren garapen-mailak eragin handia du jokalarien errendimenduan, eta, horren ondorioz, jokalarietan abantailak eta desabantailak sor ditzake. Hori ekiditeko, azkeneko urteetan jokalariak, adinaren arabera sailkatu beharrean, heltze-egoeraren arabera sailkatzen hasi dira Ingalaterrako futbol talde batzuetan. Heltze-egoeraren arabera jokalarien taldekatze horri biobanding deritzo [18]. Prozesu horrek aurresandako altueraren ehunekoa kontuan hartuta tarte ezberdinak ezarri (esate baterako, \% 85-90, \% 90-95 eta \% 95-100) eta jokalariak tarte edo taldeotan sailkatzen ditu.

Bestalde, pertsonetan heltzea momentu (heltze-momentua edo, ingelesez, timing) eta abiadura (heltze-erritmoa edo tempo) ezberdinetan gerta daiteke. Heltze-momentuak heltzearen gertakari espezifikoak (PHV, menarkia...) noiz gertatzen diren aztertzen du; eta norbanakoak goiztiar, normal edo berantiar moduan sailkatzen ditu. Heltze-abiadurak, ordea, pertsona jakin baten heltze-egoeraren progresioa zer abiaduratan gertatzen den neurtzen du (fase batetik bestera jazotzen den progresioa) [17]. 


\section{HAZKUNDEA, HELTZEA ETA LESIOAK}

\section{A. Hazkunde-abiadura lesioa pairatzeko arrisku-faktore moduan}

Hainbat dira hazkunde-abiadura bizkorra lesioekin erlazionatzen duten azalpen posibleak (1. taula). Batetik, PHVk eragindako hezurren luzatzeak hezur-dentsitatearen murriztea dakar [19], eta, ondorioz, hezur-hausturen arriskua handitzen da [20-21]. Bestetik, hezurren eta muskuluen arteko hazkunde desorekatuek zaurgarri dauden apofisien trakzio-indarra handiagotzen dute, eta badirudi horrek hazkunde-lesioen agerpena sustatzen duela [2, 22-25]. Horrez gain, gorputzeko segmentuen hazkunde bizkor eta desorekatuak aldaketa neuromuskularrak eragiten ditu [11, 12], eta horrek aldi horretan ohikoa den trakestasuna dakar. Era berean, mugikortasun eza arrisku-faktore moduan identifikatu da baina lesioekin duen harremana ez dago guztiz argi [19].

Gutxi dira faktore antropometrikoen aldaketa futbol-lesioen arrisku-faktore moduan aztertu duten ikerketak [5]. Literatura zientifikoaren arabera, PHV inguruan gertatzen diren aldaketa antropometriko bizkorrek [8-10] lesioen arriskua areagotzen dute, bai momentu horretan bertan (PHVn) eta baita ere hilabete batzuk geroago (PHV osteko fasean) [2, 22-24]. Horrela, $0,6 \mathrm{~cm} /$ hilabete baino arinago hazten diren jokalariek abiadura hori baino motelago hazi diren kirolariek baino 1,63 bider aukera gehiago dute lesionatzeko [8]. Era berean, pisua irabaztea ere arrisku-faktore moduan identifikatu izan da [8-9]. Bestalde, ikusi izan da PHV inguruan gertatzen den hanken luzeraren aldaketak bizkorra lesioen agerpenaren handiagotzearekin harremana duela bai lesio orokorrekin [8-10] eta baita, zehazki, hazkunde-lesioekin [10].

Hala ere, aipatu beharra dago orain arte egindako ikerketek metodologia ezberdinak, lagin mugatuak, jarraipen laburra... izan dituztela, eta, ondorioz, hazkundearen eta lesioen arteko harremana aztertzen duten ikerketa gehiago behar dira [5].

\section{B. Heltzea arrisku-faktore moduan}

Orain dela gutxi egindako errebisio sistematikoaren arabera, heltzearen eta lesioen arteko harremana ez dago guztiz argi. Heltze-egoerari dagokionez, PHV inguruan gorputzeko estruktura ezberdinek (hezurrak, apofisiak...) duten heldutasun eza dela eta, jokalariak lesioen aurrean zaurgarriago direla proposatu da [19-21]. Momentu horretan gorputzeko egiturak kirolak berak eragiten duen karga jasateko ez dira gai, eta, beraz, hazkunde-lesioak agertzen dira [14].

Lehen aipatu dugun bezala, gorputzaren hazkundea eta heltzea distaletik proximalera gertatzen dira [17], eta, ondorioz, heltze-prozesuan zehar lesioen kokapena ere aldatuz joan daiteke. Orain dela gutxi gure ikerketa- 
taldeak egindako analisi baten arabera, lesio bakoitza azkeneko altuera ehuneko jakin batzuetan gertatzen da [24]. Ikerketa honetan 11 urte ingurutik heldutasun-altuera lortu arte eliteko futbol akademia batean jardun zuten jokalarien jarraipen longitudinala egin genuen. Heldutasun-altuera ezagututa, lesioak heldutasun-altueraren zein ehunekotan gertatu ziren kalkulatu zen. Hazkunde-lesioak, oro har, PHV inguruan agertzen zirela behatu genuen, eta, gainera, lesioek hazkuntza- eta heltze-patroi distal-proximalari jarraitu ziotela deskribatu genuen. Horrela, gorputzeko alde distalagoetan gertatzen diren lesioak, hala nola kalkaneoko eta aurreko tuberositate tibialeko apofisitiak (Sever eta Osgood-Schlatter gaixotasunak), pelbiseko osteokondrosi-lesioak (aurreko goiko eta beheko arantza iliakoetako eta tuberositate iskiatikoko osteokondrosiak) baino lehenago agertzen dira. Bestalde, espondilolisiak are eta beranduago gertatzen dira; izan ere, enborraren hazkundea eta heltzea gorputz-adarrenen ostean gertatzen dira (2. irudia).

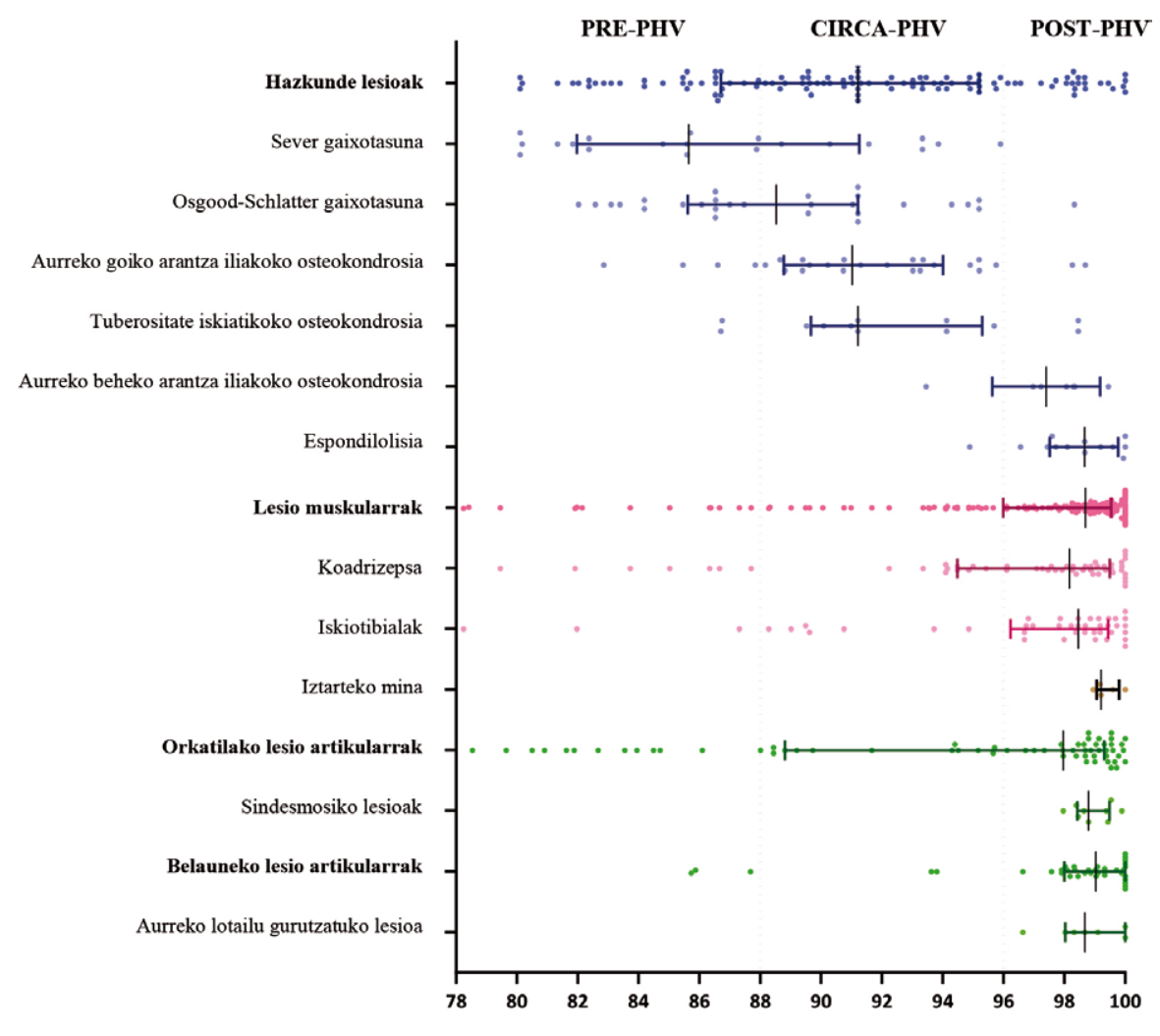

ALTUERA MAXIMOAREN EHUNEKOA (\%)

2. irudia. Altuera maximoaren ehunekoa eta lesio espezifikoak (puntu bakoitzak lesio bat irudikatzen du, eta lerroek mediana eta koartil arteko heina irudikatzen dute). Lerro eten bertikalek pre-, circa- eta post-PHV faseak bereizten dituzte. 
Bestalde, lesio muskular eta artikularrak PHVren ondoren ohikoagoak dira. Baliteke, behin apofisiak guztiz osatuta daudela, PHVk eragindako aldaketa neuromuskularrek [12] muskuluen zaurgarritasunean eragina izatea. Era berean, gorputzaren dimentsio berriek eragindako aldaketa biomekaniko eta neuromuskularrek [11-12] lesio artikularren intzidentzian eragina izan dezakete (2. irudia).

Jokalarien arteko heltze momentuko desberdintasunek (timingak) futbol-kategoria berdinean heltze-egoera oso ezberdina duten jokalariak egotea eragin dezakete. Izan ere, futbol-kategoriak adin kronologikoaren arabera antolatzen dira, eta ez adin biologikoaren arabera. Horrela, PHV inguruko kategorietan jokalari goiztiarragoak taldekide edo aurkari berantiarragoak baino handiagoak eta indartsuagoak izan ohi dira. Era berean, jokalarien arteko timing-ezberdintasunek lesioen agerpenean ere eragina izan dezaketela ikusi da. Hain zuzen ere, jokalari goiztiarren eta berantiarren arteko intzidentzia orokorrean (lesio kopuru totala entrenamendu eta partiduen denbora kontuan hartuta) ezberdintasun argirik ez dagoela ikusi den arren [25], badirudi jokalari berantiarrek hazkunde lesio gehiago pairatzen dituztela [26]. Timingaren inguruko emaitza kontrajarri eta ezberdintasun ezaren arrazoietako bat ingelesez Relative Age Effect (RAE) deritzon efektua izan daiteke.

Futbol kategoriak adin kronologikoaren arabera antolatzen dira, eta, adibidez, kadete mailan 15 eta 16 urte azpiko jokalariek jarduten dute. Hori dela eta, maila berdineko jokalarien artean 2 urteko desberdintasuna egon daiteke; esate baterako, 16 urte azpiko mailan dagoen urtarrileko jokalari baten eta 15 urte azpiko mailan dagoen eta abenduan jaio zen jokalari baten artean. Adin tarte horri adin erlatiboa deritzo (relative age). Eta horren ondorioetako bat da maila handiko kirol arrakastatsuenetan (esate baterako, futbolean) urteko lehenengo hilabeteetan jaiotako jokalari gehiago daudela urteko bukaerako hilabeteetan jaiotakoak baino. Efektu horri RAE deritzo [27]. Bai timingek eta baita RAEk jokalarien arteko heltze-ezberdintasunetan eragina izan dezakete, eta, azken finean, bi faktore horien efektua batu daitekeela esan dezakegu. Maila berdinean egonda, timing goiztiarra duen eta urtarrilean jaioa den jokalariak heltze-egoera askoz aurreratua izango du berantiarra den eta abenduan jaio den jokalariarekin konparatuta. Era berean, RAEk timingaren efektua txikitu dezake. Esate baterako, goiztiarra den eta abenduan jaioa den jokalari baten eta berantiarra den eta urtarrilean jaioa den jokalari baten artean ez da heltze-egoerari dagokionez ezberdintasun askorik egongo. Hori dela eta, etorkizunean egindako ikerketek RAE eta timing fenomenoen bateragarritasuna eta lesioekiko harremana aztertu beharko lituzkete. 
Xabier Monasterio, Susana M. ${ }^{a}$ Gil, Jon Larruskain, Jose Antonio Lekue, Iraia Bidaurrazaga-Letona

\section{ONDORIOAK}

Futbolariek lesio asko jasaten dituzte, eta horiek ondorio negatiboak eragiten dituzte haien garapenean eta errendimenduan; are gehiago, epe luzean osasunean ondorio txarrak eragin ditzakete. Hori dela eta, lesioen agerpena bultzatu dezaketen arrisku-faktoreen identifikazioa ezinbestekoa da. Hazkundearen, heltzearen eta lesioen arteko harremana guztiz argi ez dagoen arren, bai batak bai besteak lesioen intzidentzian eragina dutela ikusi da. Ondorioz, artikulu honetan zehar aipatutako aldagaien kontrola lesionatzeko arrisku handiagoa duten jokalariak identifikatzeko modua izan daiteke. Jokalariak, entrenatzaileak eta zerbitzu medikoetako kideak hazkundeari eta heltzeari buruz kontzientziatzea ezinbestekoa da entrenamenduak, prebentzio- eta errehabilitazio-estrategiak, eta kirolera bueltatzeko programak diseinatzeko orduan. Izan ere, jokalarien garapenean parte hartzen duten profesional guztien parte-hartze aktiboa behar-beharrezkoa da jokalarien osasuna bermatu eta, hala, lehenengo taldera heltzeko aukerak handitzeko.

\section{ESKER ONAK}

X.M.C. Eusko Jaurlaritzak finantzatutako Doktoratu Aurreko Programako laguntza jaso du (PRE_2019_2_0108).

\section{BIBLIOGRAFIA}

[1] JONES, S., ALMOUSA, S., GIBB, A., ALLAMBY, N., MULLEN, R., ANDERSEN, T. E. eta WILLIAMS, M. 2019. «Injury Incidence, Prevalence and Severity in High-Level Male Youth Football: A Systematic Review». Sports Medicine, 49(12), 1879-1899.

[2] BULT, H. J., BARENDRECHT, M. eta TAK, I. J. R. 2018. «Injury Risk and Injury Burden Are Related to Age Group and Peak Height Velocity Among Talented Male Youth Soccer Players». Orthopaedic Journal of Sports Medicine, 6(12), 2325967118811042.

[3] EKSTRAND, J. 2013. «Keeping your top players on the pitch: The key to football medicine at a professional level». British Journal of Sports Medicine, 47(12), 723-724.

[4] HÄGGLUND, M., WALDÉN, M., MAGNUSSON, H., KRISTENSON, K., BENGTSSON, H. eta EKSTRAND, J. 2013. «Injuries affect team performance negatively in professional football: An 11-year follow-up of the UEFA Champions League injury study». British Journal of Sports Medicine, 47(12), 738-742.

[5] SWAIN, M., KAMPER, S. J., MAHER, C. G., BRODERICK, C., MCKAY, D. eta HENSCHKE, N. 2018. «Relationship between growth, maturation 
and musculoskeletal conditions in adolescents: A systematic review». British Journal of Sports Medicine, 52(1), 1246-1252.

[6] LARRUSKAIN, J., LEKUE, J. A., MARTIN-GARETXANA, I., BARRIO, I., MCCALL, A. eta GIL, S. M. (berrikuspenean). «Injuries have a negative impact on player progression in an elite football academy».

[7] PRICE, R. J., HAWKINS, R. D., HULSE, M. A. eta HODSON, A. 2004. «The Football Association medical research programme: An audit of injuries in academy youth football». British Journal of Sports Medicine, 38(4), 466-471.

[8] KEMPER, G. L. J., VAN DER SLUIS, A., BRINK, M. S., VISSCHER, C., FRENCKEN, W. G. P. eta ELFERINK-GEMSER, M. T. 2015. «Anthropometric Injury Risk Factors in Elite-standard Youth Soccer». International Journal of Sports Medicine, 36(13), 1112-1117.

[9] ROMMERS, N., RÖSSLER, R., GOOSSENS, L., VAEYENS, R., LENOIR, M., WITVROUW, E. eta D'HONDT, E. 2020. «Risk of acute and overuse injuries in youth elite soccer players: Body size and growth matter». Journal of Science and Medicine in Sport, 23(3), 246-251.

[10] WIK, E. H., MARTÍNEZ-SILVÁN, D., FAROOQ, A., CARDINALE, M., JOHNSON, A. eta BAHR, R. 2020. «Skeletal maturation and growth rates are related to bone and growth plate injuries in adolescent athletics». Scandinavian Journal of Medicine \& Science in Sports, [Epub ahead of print]

[11] READ, P. J., OLIVER, J. L., MYER, G. D., DE STE CROIX, M. B. A., BELSHAW, A. eta LLOYD, R. S. 2018. «Altered landing mechanics are shown by male youth soccer players at different stages of maturation». Physical Therapy in Sport, 33(1), 48-53.

[12] RADNOR, J. M., OLIVER, J. L., WAUGH, C. M., MYER, G. D., MOORE, I. S. eta LLOYD, R. S. 2018. «The Influence of Growth and Maturation on Stretch-Shortening Cycle Function in Youth». Sports Medicine, 48(1), 57-71.

[13] LAPRADE, R. F., AGEL, J., BAKER, J., BRENNER, J. S., CORDASCO, F. A., CÔTÉ, J., ... eta PROVENCHER, M. T. 2016. «AOSSM Early Sport Specialization Consensus Statement». Orthopaedic Journal of Sports Medicine, 4(4), 2325967116644241.

[14] LEPPÄNEN, M., PASANEN, K., CLARSEN, B., KANNUS, P., BAHR, R., PARKKARI, J., ... eta VASANKARI, T. 2019. «Overuse injuries are prevalent in children's competitive football: A prospective study using the OSTRC Overuse Injury Questionnaire». British Journal of Sports Medicine, 53(3), 165-171.

[15] SOBRADILlO, B., AGUIRRE A., ARESTI, U., BILBAO, A., FERNÁNDEZ-RAMOS, A., eta LIZÁRRAGA, A. 2004. "Curvas y tablas de crecimiento. Estudio longitudinal y transversal». Fundación Faustino Orbegozo Eizaguirre. Bilbao.

[16] MALINA, RM., BOUCHARD, C. eta BAR-OR, O. 2004. «Growth, maturation, and physical activity». (2nd edition). Human Kinetics. Champaign, Illinois. 
Xabier Monasterio, Susana M. ${ }^{a}$ Gil, Jon Larruskain, Jose Antonio Lekue, Iraia Bidaurrazaga-Letona

[17] MAlinA, R. M., ROGOL, A. D., CUMMING, S. P., COELHO E SILVA, M. J. eta FIGUEIREDO, A. J. 2015. «Biological maturation of youth athletes: Assessment and implications». British Journal of Sports Medicine, 49(13), 852-859.

[18] MALINA, R. M., CUMMING, S. P., ROGOL, A. D., COELHO-E-SILVA, M. J., FIGUEIREDO, A. J., KONARSKI, J. M. eta KOZIEŁ, S. M. 2019. «Bio-Banding in Youth Sports: Background, Concept, and Application». Sports Medicine, 49(11), 1671-1685.

[19] FAULKNER, R. A., DAVISON, K. S., BAILEY, D. A., MIRWALD, R. L. eta BAXTER-JONES, A. D. G. 2006. «Size-corrected BMD decreases during peak linear growth: Implications for fracture incidence during adolescence». Journal of Bone and Mineral Research, 21(12), 1864-1870.

[20] BLIMKIE CAMERON J. R., LEFEVRE, J., BEUNEN, G. P., RENSON, R., DEQUEKER, J. eta DAMME, P. van. 1991. «Fractures,phsical activity and growth velocity». Medicine \& Science in Sports \& Exercise, 25(7), 801-808.

[21] ENGEBRETSEN L, STEFFEN K, B. R., ... eta STEEN, H. 2010. «The International Olympic Committee consensus statement on age determination in high-level young athletes». British Journal of Sports Medicine, 44(1), 476484.

[22] MAterne, O., FAROOQ, A., JOHnSON, A., GREIG, M. eta MCNAUGHTON, L. 2016. «Relationship between injuries and somatic maturation in highly trained youth soccer players». International Research in Science and Soccer II. Abingdon: Routledge, 182-192.

[23] VAN DER SLUIS, A., ELFERINK-GEMSER, M. T., COELHO-E-SILVA, M. J., NIJBOER, J. A., BRINK, M. S. eta VISSCHER, C. 2014. «Sport injuries aligned to Peak Height Velocity in talented pubertal soccer players». International Journal of Sports Medicine, 35(4), 351-355.

[24] MONASTERIO, X., GIL, S. M., BIDAURRAZAGA-LETONA, I., LEKUE, J. A., SANTISTEBAN, J., DIAZ-BEITIA, G., MARTIN-GARETXANA, I., LARRUSKAIN, J. 2020. «Injuries according to the percentage of adult height in an elite football academy». Journal of Science and Medicine in Sport, prentsan)

[25] JOHNSON, D. M., WILLIAMS, S., BRADLEY, B., SAYER, S., MURRAY FISHER, J. eta CUMMING, S. 2019. «Growing pains: Maturity associated variation in injury risk in academy football». European Journal of Sport Science. 8(1), 1-9.

[26] VAN DER SLUIS, A., ELFERINK-GEMSER, M. T., COELHO-E-SILVA, M. J., NIJBOER, J. A., BRINK, M. S. eta VISSCHER, C. 2014. «Importance of peak height velocity timing in terms of injuries in talented soccer players». International Journal of Sports Medicine, 36(4), 327-332.

[27] GIL, S. M., BIDAURRAZAGA-LETONA, I., MARTIN-GARETXANA, I., LEKUE, J. A., A., LARRUSKAIN, J. 2019. «Does birth date influence career attainment in professional soccer?». Science and Medicine in Football, doi:10.1080/24733938.2019.1696471. 